\title{
Reอ绝es
}

\section{Coral obligate filefish masquerades as branching coral}
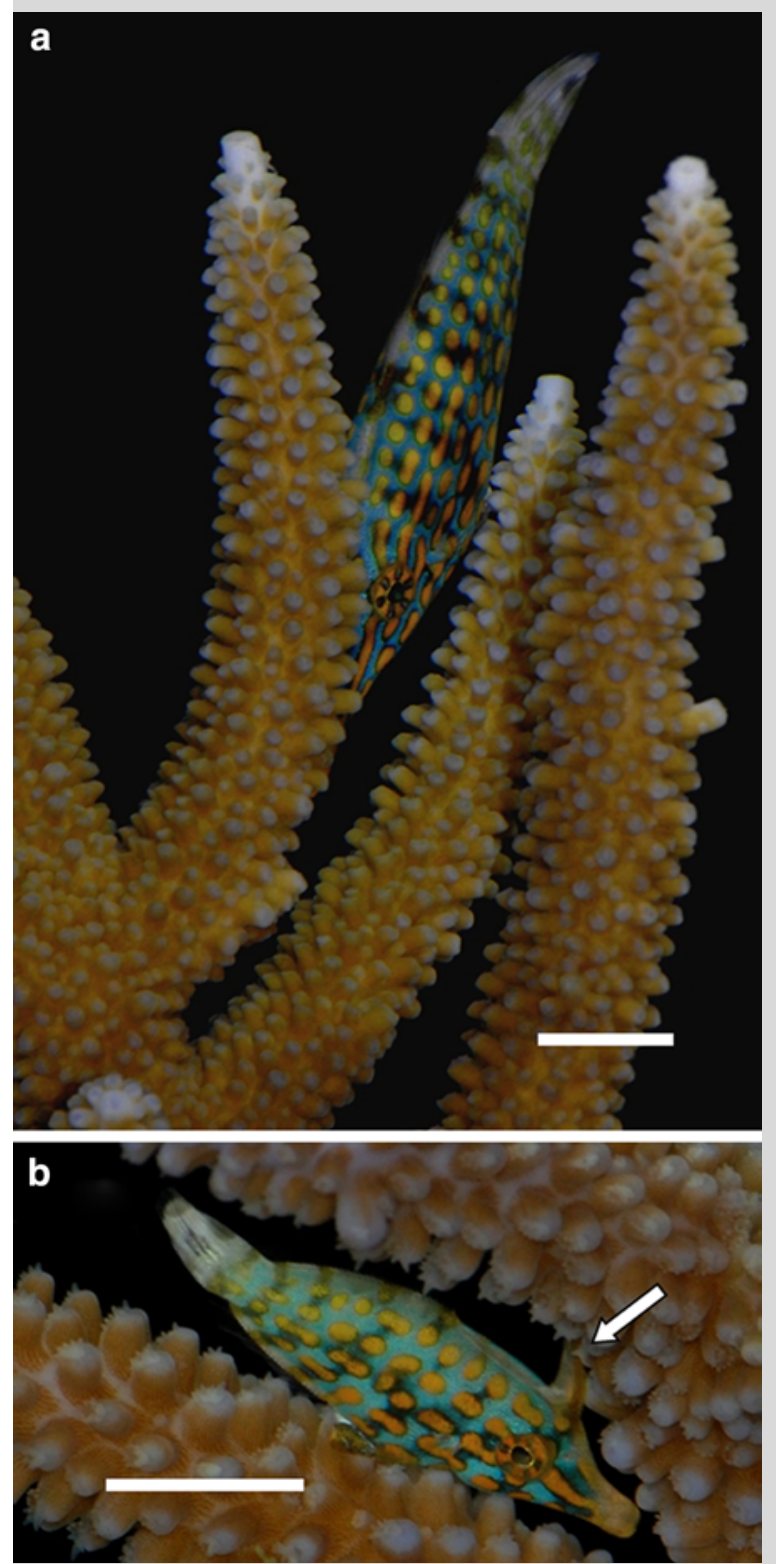

Fig. 1 Crepuscular and nocturnal resting position of an adult (a) and newly settled recruit (b) amongst branching Acropora coral. Note the dorsal spine used to lock fish onto branch. Scale bars represent $10 \mathrm{~mm}$
Masquerade occurs when an organism uses its coloration or shape to resemble an inedible object, causing it to be misidentified by potential predators, rather than simply remaining undetected (crypsis) (Skelhorn et al. 2010). The harlequin filefish, Oxymonacanthus longirostris (Bloch \& Schneider, 1801), is a highly specialised species, which almost exclusively uses Acropora corals for food and as habitat (Kokita and Nakazono 2001). This species' behaviour during crepuscular and nocturnal periods, along with body form and colour pattern, suggests it masquerades as the branching Acropora species with which it associates. Prior to sunset, a fish will select a position amongst branching Acropora, locking itself onto the coral using its first dorsal spine. Anal, dorsal and caudal fins are depressed streamlining the fish into a branchlike point (Fig. 1a, b). This position is then maintained until after dawn. The site selected on the coral is often amongst the upper branches and relatively exposed, possibly where masquerade would be most important. If disturbed, a fish will immediately return to its original position. In this orientation, the species' colour pattern appears as rows of pale polyps against a darker background with the caudal fin appearing as the lighter growing tip. This masquerade allows fish to avoid detection during the periods of highest predation risk. Behavioural observations of 22 adults and 4 newly settled recruits were undertaken at Lizard Island, Australia during November and December 2010. The described behaviour was observed in all adults and recruits nightly during the observation period. Comparable behaviour has also been observed in the similar Red Sea species, Oxymonacanthus halli (Marshall, 1952) (Wüest, 1993). To the author's knowledge, this is the first documented example of a fish species masquerading as a scleractinian coral.

Acknowledgments We thank Lizard Island Research Station for logistical support \& M. Welch for assistance with photographs.

\section{References}

Kokita T, Nakazono A (2001) Rapid response of an obligately corallivorous filefish Oxymonacanthus longirostris (Monacanthidae) to a mass coral bleaching event. Coral Reefs 20:155-158

Skelhorn J, Rowland HM, Speed MP, Ruxton GD (2010) Masquerade: Camouflage without crypsis. Science 327:51

Wüest U (1993) Über das schlafverhalten des harlekin-feilenfisches Oxymonacanthus halli. Nat Mus 123:56-59

R. M. Brooker $(\bowtie) \cdot$ P. L. Munday · G. P. Jones

ARC Centre of Excellence for Coral Reef Studies, James Cook University, Townsville, QLD 4811, Australia

e-mail: rohan.brooker@my.jcu.edu.au 